\title{
The influence of protection system failures and preventive maintenance on protection systems in distribution systems
}

by

J.J. Meeuwsen

Delft University of Technology

Mekelweg 4

2628 CD Delft

The Netherlands

\author{
W.L. Kling \\ Delft University of Technology \\ Mekelweg 4 \\ 2628 CD Delft \\ The Netherlands
}

\author{
W.A.G.A. Ploem \\ NV PNEM Facilitair Bedrijf \\ Koningsweg $101^{\circ}$ \\ $5200 \mathrm{BZ}$ 's-Hertogenbosch \\ The Netherlands
}

\begin{abstract}
Protection systems in power systems can fail either by not responding when they should (failure to operate) or by operating when they should not (false tripping). The former type of failure is particularly serious since it may result in the isolation of large sections of the network. However, the probability of a failure to operate can be reduced by carrying out preventive maintenance on protection systems. This paper describes an approach to determine the impact of preventive maintenance on protection systems on the reliability of the power supply to customers. The proposed approach is based on Markov models.
\end{abstract}

\section{Introduction}

An electric power system comprises generation, transmission and distribution. Although distribution systems have received less attention than generating systems and composite generating and transmission systems, analysis of the customer failure statistics shows that distribution systems are responsible for as much as $90 \%$ of the unavailability of supply to a customer [1]. Such statistics reinforce the need to be concerned with the reliability evaluation of distribution systems.

An important aspect of the reliability of load points in a distribution system is the reliability of protection systems. A protection system is designed to fulfill two major functions [2,3]:

96 WM 065-3 PWRD A paper recommended and approved by the IEEE Power System Relaying Committee of the IEEE Power Engineering Society for presentation at the 1996 IEEE/PES Winter Meeting, January 21-25, 1996, Baltimore, MD. Manuscript submitted July 7, 1995; made available for printing December 8, 1995.
* quick isolation of faults after their occurrence

* protection of major power system components from possible damage by abnormal voltage or current

In general, a protection system consists of three or four subsystems [4]: input transducers, protection relays, communication systems (if used) and circuit breakers as given in figure 1. A detailed knowledge of these subsystems and their failure modes is essential to the protection engineer, but from an overall system point of view, measurement transformers, communication channels, protection relays and circuit breakers can be treated as one single component. Therefore, these subsystems are referred to in this discussion simply as the protection or by $\mathrm{P}$.

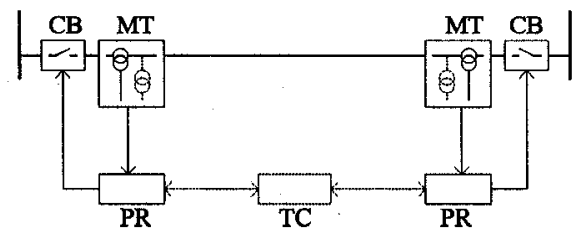

$$
\begin{aligned}
& \text { CB : Circuit Breaker } \\
& \text { MT : Measurement Transformer(s) } \\
& \text { PR : Protection Relay } \\
& \text { TC : Telecommunication Channel }
\end{aligned}
$$

Figure 1. General protection system scheme

In earlier studies, distiction was made between the following two major breaker or protection system failure modes in power systems $[3,5]$ :

* failure to operate when the operation is called for

* false tripping operation

\section{Failure to operate}

When a system fault occurs and one or more of the breakers controlling the protection zone fails to trip, back-up or secondary protection must operate which is likely to outage a greater section of the system with a more significant impact on system operation. This is illustrated in figure 2. The upper system 
shows a healthy meshed distribution system (all circuit breakers closed). The lower two systems show two possible faulted situations due to failures to operate. The circuit breaker which is marked with a cross is the faulted circuit breaker. The dotted lines represent the isolated components. From figure 2 it can be seen that this failure mode is very important and should be recognized. A failure to operate is generally due to the protection having developed an unrevealed fault since it was last operated or tested. The protection then remains in a dormant failure-to-operate state until a power system faults occurs, or until preventive maintenance is performed.

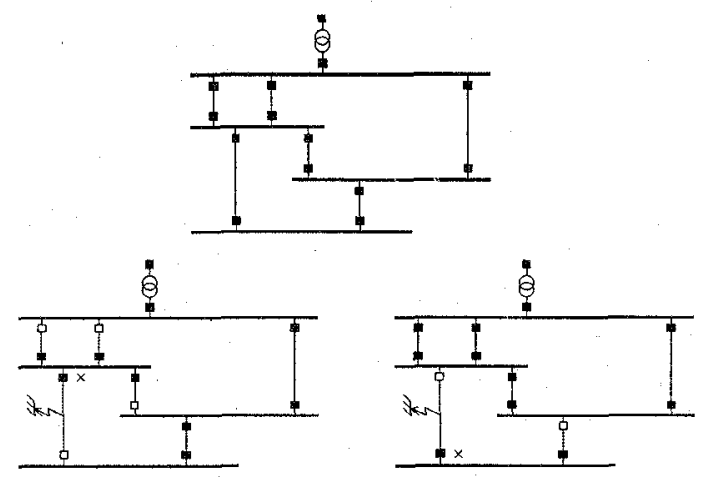

Figure 2. Two possible faulted situations due to failures to operate

\section{False trips}

These are due to the inadvertent opening of a breaker, again as a result of malfunction of the protection relay or associated equipment. This failure mode also includes manual operating errors. Figure 3 demonstrates the effect of false trips.
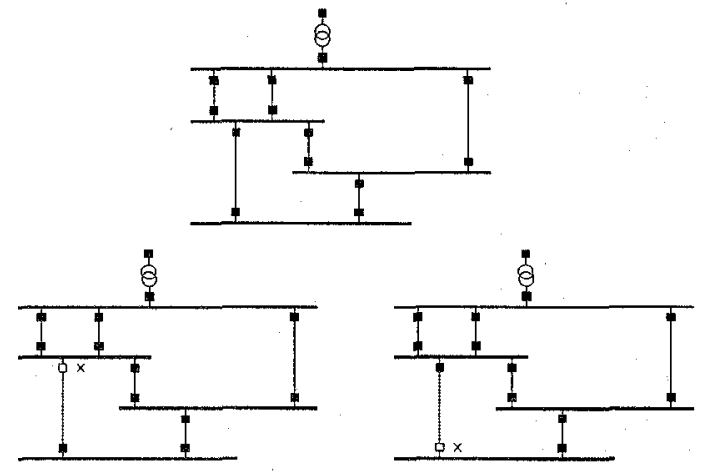

Figure 3. Two possible faulted situations due to false trips

This article describes an approach to evaluate the effect of protection system failures on the reliability indices of supply to a customer. Also the usefulness of performing preventive maintenance on protection systems is demonstrated. The paper stresses the reliability evaluation and assessment in meshed distribution systems although the techniques can also be used for radial systems.

The paper is organized as follows. First the paper presents the reliability model for one single component on which the reliability calculations are based. This is followed by a discussion on some of the details related to the practical implementation of the model in the reliability analysis of a system, consisting of $\mathbf{n}$ components. Next, some results of reliability evaluations of an illustrative distribution system of the PNEM (a utility in the southern part of the Netherlands) are presented. Finally, there are some concluding remarks.

\section{Reliability model of a component}

Before the proposed modelling technique, a short list of symbols is presented.

List of symbols

$\lambda_{i}$ failure rate of the protected component $i$ [failures/year]

$\lambda_{f t}$ failure rate of a false trip of the protection $P$ [failures/year]

$\lambda_{f o} \quad$ failure rate of a failure to operate of the protection P [failures/year]

$\mu_{i} \quad$ repair rate of the protected component i [repairs/hour]

$\mu_{P} \quad$ repair rate of the protection P [repairs/hour]

$\mu_{\text {insp }}$ repair rate of preventive maintenance on the protection $\mathrm{P}$ after inspection [repairs/hour]

$\theta_{\text {insp }}$ inspection rate of the protection $\mathrm{P}$ [inspections/year]

$\psi_{i} \quad$ switching rate of the protected component $\mathrm{i}$ [switching operations/hour]

$P_{u m} \quad$ probability of unsuccessful maintenance

UP item is in a good state

DN item is in a failed state

INSP item is being inspected and is therefore not available

ISO item is isolated and is therefore not available

If the protection is $100 \%$ reliable, each protected component $\mathrm{i}$ can be represented by a two-state Markov model as given in figure 4 , i.e. i UP (in service) or i DN (out for corrective maintenance).

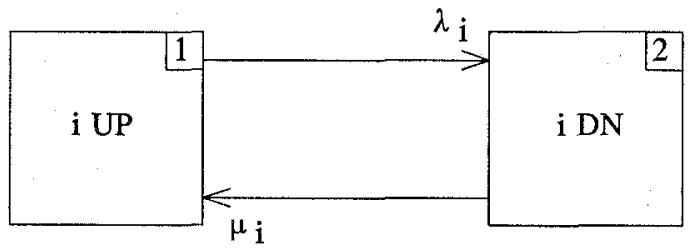

Figure 4. Two-state Markov model 
If the protection of component $i$ is not $100 \%$ reliable, the protected component $i$ cannot be represented as in figure 4 . A more detailed model then becomes necessary $[4,6,7]$. A multi-state Markov model which includes the two protection system failure modes (failures to operate and false trips) and performing preventive maintenance on protection systems is given in figure 5 . This figure shows the detailed states of component $i$ and its surrounding protection $\mathbf{P}$ individually.

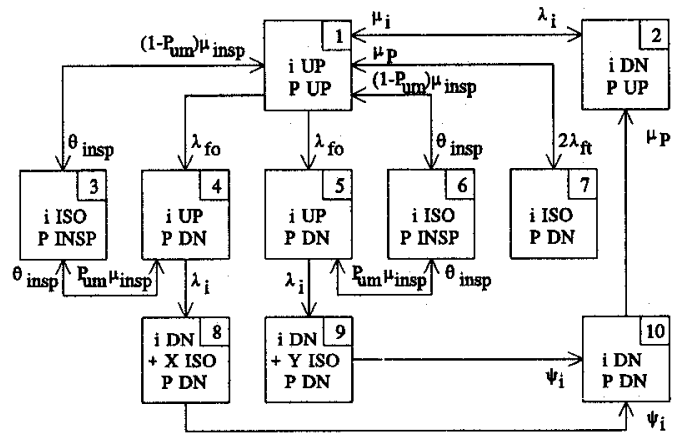

Figure 5. Multi-state Markov model

* State 1 represents usual operation with both $\mathrm{i}$ and P UP.

* When $\mathrm{i}$ goes $\mathrm{DN}$, state 2 is entered, while $\mathrm{P}$ detects and isolates the failure. In this state, the DN $\mathrm{i}$ is inspected, repaired, and returned to state 1 , which usually takes several hours or, perhaps, days to complete.

* When $P$ gives a false trip, the transition is to state 7. Because a false trip of the protections on both sides of $i$ has the same impact on the system (figure 3), both failures are incorporated in a single state. In state 7 , the DN P is inspected, repaired, and returned to state 1 .

* if $\mathrm{P}$ goes DN while in state 1 , due to a failure to operate, the transition is to state 4 or to 5 . In state 4 , the protection on one side of $i$ is unready to respond. In state 5 , the protection on the other side of $i$ is unready to respond.

* If $i$ goes DN while the system is in either state 4 or 5 , the transition is not detected and back-up protection systems on adjacent components must act to isolate i. Back-up protection systems order $i$, together with adjacent connected components $\mathrm{X}$ or $\mathrm{Y}$ to go ISO. These actions cause a transition to state 8 respectively state 9 . The system must be inspected, and the good adjacent components $\mathrm{X}$ or $\mathrm{Y}$ restored to service, usually by manual switching, which transfers the system to state 10 .

* From this point, P is repaired to UP with transition to state 2. Then $i$ is repaired to UP with transition to state 1 . Simultaneous repair can be considered by introducing a slight complication, but would result in little change since the repair- time of $i$ is usually longer than the repairtime of $P$.

* The inspection or preventive maintenance states are given by the states 3 and 6 . In state 3 the protection on one side of $i$ is inspected. This state can be reached from state 1 or state 4 . In state 6 the protection on the other side of $i$ is inspected. State 6 can be reached from state 1 or state 5 . The effect of unsuccessful maintenance is taken into account by the probability, $P_{u n}$.

Using the frequency balance approach [8,9], the probability of state $\mathrm{j}$ for component i, $P_{i, j}$, $\mathrm{j} \in\{1,2, \ldots, 10\}$, can be evaluated. This probability is a function of the transition rates and is given by:

$$
P_{i, j}=f_{j}\left(\lambda_{i}, \lambda_{f o}, \lambda_{f o}, \mu_{i}, \mu_{P}, \mu_{i n s p}, \theta_{i n s p}, \Psi_{i}\right)
$$

In the same way, the frequency, $F_{i, j}$, and mean duration, $D_{i, j}$, of state $\mathrm{j}$ for component $\mathrm{i}$ are given by:

$$
F_{i, j}=g_{j}\left(\lambda_{i}, \lambda_{f o}, \lambda_{f o}, \mu_{i}, \mu_{P}, \mu_{i n s p}, \theta_{i n s p}, \Psi_{i}\right)
$$

and:

$$
D_{i, j}=h_{j}\left(\lambda_{i}, \lambda_{f o}, \lambda_{f t}, \mu_{i}, \mu_{P}, \mu_{i n s p}, \theta_{i n s p}, \Psi_{i}\right)
$$

The relation between (1), (2) en (3) is given by:

$$
\boldsymbol{P}_{i, j}=\boldsymbol{F}_{i, j} D_{i, j}
$$

From figure 5, it can be seen that the state-space model can be reduced to a four-state model by combining several states, according to:

* state A: component $i$ is in service

* state B: component $\mathrm{i}$ is isolated or failed

* state $\mathrm{C}$ : component $\mathrm{i}$ is failed and $\mathrm{X}$ healthy components are isolated

* state $\mathrm{D}$ : component $\mathrm{i}$ is failed and $\mathrm{Y}$ healthy components are isolated

Using reduction rules for Markov models [10], the probability, $P_{i, x}$, frequency, $F_{i, x}$, and mean duration, $D_{i, x}, \mathrm{x} \in\{\mathrm{A}, \mathrm{B}, \mathrm{C}, \mathrm{D}\}$, for component $\mathrm{i}$ can be evaluated. Again, they are certain functions of the transition rates, used in the model, i.e.

$$
\begin{aligned}
& P_{i, x}=f_{x}\left(\lambda_{i}, \lambda_{f o}, \lambda_{f t}, \mu_{i}, \mu_{P}, \mu_{i n s p}, \theta_{i n s p}, \Psi_{i}\right) \\
& F_{i, x}=g_{x}\left(\lambda_{i}, \lambda_{f o}, \lambda_{f i}, \mu_{i}, \mu_{P}, \mu_{i n s p}, \theta_{i n s p}, \Psi_{i}\right) \\
& D_{i, x}=h_{x}\left(\lambda_{i}, \lambda_{f o}, \lambda_{f t}, \mu_{i}, \mu_{P}, \mu_{i n s p}, \theta_{i n s p}, \Psi_{i}\right)
\end{aligned}
$$

For example, the probabilities $P_{i, A}, P_{i, B}, P_{i, C}$ and $P_{i, D}$ 
are given by:

$$
\begin{gathered}
P_{i, A}=P_{i, 1}+P_{i, 4}+P_{i, 5} \\
P_{i, B}=P_{i, 2}+P_{i, 3}+P_{i, 6}+P_{i, 7}+P_{i, 10} \\
P_{i, C}=P_{i, 8} \\
P_{i, D}=\dot{P}_{i, 9}
\end{gathered}
$$

\section{Reliability model of a system}

A reliability evaluation of a power system is a simulation and load-flow analysis of a list of possible contingencies for the system. For each contingency, the probability, frequency and mean duration of its occurence can be evaluated. For example: in a system with $\mathrm{n}$ components, the probability of $\mathrm{n}-1$ components in service, except component $\mathrm{m}, P_{m}(1)$, is given by:

$$
P_{m}(1)=P_{m, B} \prod_{k=1, k \neq m}^{n} P_{k, A}
$$

and the probability of $(1+X)$ components not in service due to a failure to operate of a protection of component $\mathrm{q}, P_{q}(1+\mathrm{X})$, can be evaluated by:

$$
P_{q}(1+X)=P_{q, C} \prod_{k=1, k \neq q, k \notin X^{q}}^{n} P_{k, A}
$$

where:

$X^{\dot{q}}$ set of $\mathrm{X}$ isolated components due to a failure to operate of the protection of component $\mathrm{q}$

These contingencies are called contingencies of first respectively $(1+\mathrm{X})^{\text {th }}$ order, because one respectively $(1+X)$ components are not in service.

With a load-flow analysis for each state of the distribution system, it is shown which components are overloaded and which load points become isolated due to the occurrence of a certain contingency. The overall probability for the isolation of load point $\mathrm{k}$, $P(k)$, can be evaluated by adding all probabilities of events i leading to the isolation of load point $k$ :

$$
P(k)=\sum_{i=1}^{t_{k}} P_{Y}(Z)_{i}
$$

In the same way, the frequency of isolation of load point k, $F(k)$, can be evaluated:

$$
F(k)=\sum_{i=1}^{t_{k}} F_{Y}(Z)_{i}
$$

where:

$P(k) \quad$ probability of isolation of load point $\mathrm{k}$

$F(k)$ frequency of isolation of load point $\mathrm{k}$

$t_{k} \quad$ number of contingencies leading to isolation of load point $\mathrm{k}$

$P_{Y}(Z)_{i}$ probability of contingency $\mathrm{i}$ leading to isolation of load point $\mathrm{k}$

$F_{Y}(Z)_{i}$ frequency of contingency i leading to isolation of load point $k$

$$
\begin{array}{ll}
Y & \subset\{1,2, \ldots, \mathrm{n}\} \\
Z & \in\{1,2, \ldots, \mathrm{n}\}
\end{array}
$$

The relation between the probability, frequency and mean duration of isolation of load point $\mathrm{k}, P(k)$, $F(k)$ and $D(k)$ is given by:

$$
P(k)=F(k) D(k)
$$

\section{Distribution system studies}

A digital computer program has been developed at the Delft University of Technology. The basic procedure has been discussed in the previous sections. The application of the previously discussed approaches is illustrated in three case studies for an existing meshed $10 \mathrm{kV}$-distribution system of the PNEM. This system, shown in figure 6 , has 4 substations. The busbar peak loads are given in this figure.

All $10 \mathrm{kV}$-distribution systems of the PNEM are directly supplied from the $150 \mathrm{kV}$-grid by two transformers, where the second transformer is a spare transformer. The distribution systems of the PNEM comprises a meshed operated part (subtransmission system) and a radial operated part (real distribution system). The radial operated part is not given in figure 6 . The following assumptions are made:

\section{Assumptions}

* The radial operated part of the distribution system is not considered. The loads, which are supplied by the radial operated part of the distribution system are grouped together on the load points of figure 6 .

* It is assumed that the $150 / 10 \mathrm{kV}$-supply on busbar 1 in figure 6 is $100 \%$ reliable.

* It is assumed that the $10 \mathrm{kV}$-busbars in figure 6 are $100 \%$ reliable. 
* The mean repairtime of the protection is estimated as 2 hours $\left(\mu_{P}=0.5\right.$ repairs/hour)

* The mean time of performing preventive maintenance on the protection is also estimated as 2 hours ( $\mu_{\text {insp }}=0.5$ repairs $/$ hour $)$

* The manual switching time is estimated as 1 hour $\left(\psi_{i}=1.0\right.$ switching operation/hour)

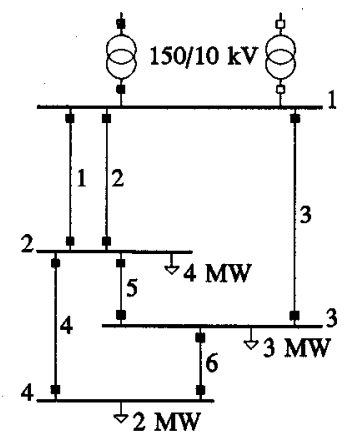

Figure 6. Distribution system network

The additional basic distribution system data is shown in table 1 .

The following case studies are performed for the distribution system, shown in figure 6 .

Case 1

Considering the system configuration in figure 6 , it is assumed that all protections are $100 \%$ reliable (no failures to operate and no false trips occur). Therefore, no preventive maintenance is performed. For each load point, three reliability indices are evaluated:

* probability of failure of load point $\mathrm{k}, P(k)$

* frequency of failure of load point $\mathrm{k}, F(k)$

* mean duration of failure of load point $\mathrm{k}, D(k)$

It should be noted that under the assumptions made in this case study, the Markov model given in figure 5 reduces to the Markov model given in figure 4, because certain transition rates become zero.

Case 2

Considering the system in figure 6 , it is assumed that the protections are not $100 \%$ reliable $\left(\lambda_{f o}=\right.$ $\lambda_{f t}=0.01$ failure/year). Further it is assumed that no preventive maintenance on the protections is carried out. As in case 1 , three reliability indices are evaluated.

Case 3

Considering the system in figure 6 , it is assumed that the protections are not $100 \%$ reliable $\left(\lambda_{f o}=\right.$ $\lambda_{f t}=0.01$ failure/year). Further it is assumed that preventive maintenance on the protections is carried out. In this case study, the effect of preventive maintenance on the expected energy not supplied per year (EENS) in the system is evaluated. This index is derived from the individual load point indices which are calculated using several values of the probability of unsuccesful maintenance, $P_{u m}$, and a varying maintenance interval.

The results shown in the following paragraphs provide a variety of information that can be obtained by using the proposed techniques.

\section{Results of case 1}

The annualized load point indices calculated using the digital computer program are given in table 2 . Independent outages are considered up to the third level. This table indicates that load point 1 is $100 \%$ reliable. This is the result of:

* the assumption that all protection systems are $100 \%$ reliable. Therefore, faulted regions cannot increase due to actions of the back-up protection.

* the assumption that the $150 / 10 \mathrm{kV}$-supply is $100 \%$ reliable.

* the assumption that the $10 \mathrm{kV}$-busbars are $100 \%$ reliable.

All other load points are not $100 \%$ reliable, because certain overlapping combinations of faults can lead to isolated load points. For the same reasons, mentioned above, the reliability indices are extremely small. Moreover, it must be stated that the $10 \mathrm{kV}$ distribution system is designed with (n-1) redundancy, i.e. a first-order contingency may never result in a load point disconnection due to isolation or overload. Therefore, the outage times of the busbars 2 , 3 and 4 are the result of second and/or third order independent overlapping outages. Their outage durations are therefore given by 25.0 hours $/ 2(=12.5$ hours) respectively 25.0 hours $/ 3 \quad(=8.33$ hours), which are repairtimes (and not switching times).

\section{Results of case 2}

The annualized load point indices are given in table 3. From this table it appears that none of the load points are $100 \%$ reliable. This is the result of the assumption that protection systems are not $100 \%$ reliable. Therefore, faulted regions can increase due to actions of the back-up protection. A significant increase in the annualized load point indices can be seen from tables 2 and 3 . It should be noted that the mean duration of a disturbance is almost equal to 1 hour for all load points. This is the result of the assumption that the switching rate, $\psi_{i}$, is chosen as 1.0 switching operation/hour.

\section{Results of case 3}

Figure 7 plots the calculation results for case study 3. Again the probabilities of failure of the individual load points are calculated as a function of the main- 


\begin{tabular}{||c|c|c|c|c|c||}
\hline Cable & $\begin{array}{c}\text { Length } \\
{[\mathrm{km}]}\end{array}$ & $\begin{array}{c}\text { Impedance } \\
{[\Omega]}\end{array}$ & $\begin{array}{c}\text { Current rating } \\
{[\mathrm{A}]}\end{array}$ & $\begin{array}{c}\text { Failure rate } \\
{\left[\text { [year }^{-1}\right]}\end{array}$ & $\begin{array}{c}\text { Repairtime } \\
{[\text { [hours] }}\end{array}$ \\
\hline 1,2 & 5 & $0.650+\mathrm{j} 0.375$ & 310 & 0.0745 & 25.0 \\
3 & 7 & $0.910+\mathrm{j} 0.525$ & 310 & 0.1043 & 25.0 \\
4 & 4 & $0.864+\mathrm{j} 0.332$ & 225 & 0.0596 & 25.0 \\
5 & 3 & $0.648+\mathrm{j} 0.249$ & 225 & 0.0447 & 25.0 \\
6 & 2 & $0.432+\mathrm{j} 0.166$ & 225 & 0.0298 & 25.0 \\
\hline
\end{tabular}

Table 1. Distribution system data

\begin{tabular}{|c|c|c|c|}
\hline Load point & Probability & $\begin{array}{c}\text { Frequency } \\
\text { [year-1 }\end{array}$ & $\begin{array}{c}\text { Duration } \\
\text { [hours] }\end{array}$ \\
\hline 1 & $0.00 \mathrm{e}+00$ & $0.00 \mathrm{e}+00$ & $0.00 \mathrm{e}+00$ \\
2 & $1.36 \mathrm{e}-11$ & $1.42 \mathrm{e}-08$ & $8.33 \mathrm{e}+00$ \\
3 & $2.33 \mathrm{e}-11$ & $2.44 \mathrm{e}-08$ & $8.33 \mathrm{e}+00$ \\
4 & $1.46 \mathrm{e}-08$ & $1.02 \mathrm{e}-05$ & $1.25 \mathrm{e}+01$ \\
\hline
\end{tabular}

Table 2. Results for case study 1

\begin{tabular}{|c|c|c|c|}
\hline Load point & Probability & $\begin{array}{c}\text { Frequency } \\
\text { [year-1 }\end{array}$ & $\begin{array}{c}\text { Duration } \\
\text { [hours] }\end{array}$ \\
\hline 1 & $2.76 \mathrm{e}-06$ & $2.41 \mathrm{e}-02$ & $1.00 \mathrm{e}+00$ \\
2 & $6.21 \mathrm{e}-06$ & $5.43 \mathrm{e}-02$ & $1.00 \mathrm{e}+00$ \\
3 & $5.20 \mathrm{e}-06$ & $4.54 \mathrm{e}-02$ & $1.00 \mathrm{e}+00$ \\
4 & $4.32 \mathrm{e}-06$ & $3.76 \mathrm{e}-02$ & $1.00 \mathrm{e}+00$ \\
\hline
\end{tabular}

Table 3 . Results for case study 2

tenance interval (or maintenance frequency, which is the reciprocal value of the maintenance interval). From these indices the expected energy not supplied per year (EENS) in the system can be derived by using the typical load factor of the system. Figure 7 is calculated for several values of the probability of unsuccesful maintenance, $P_{u m}$.

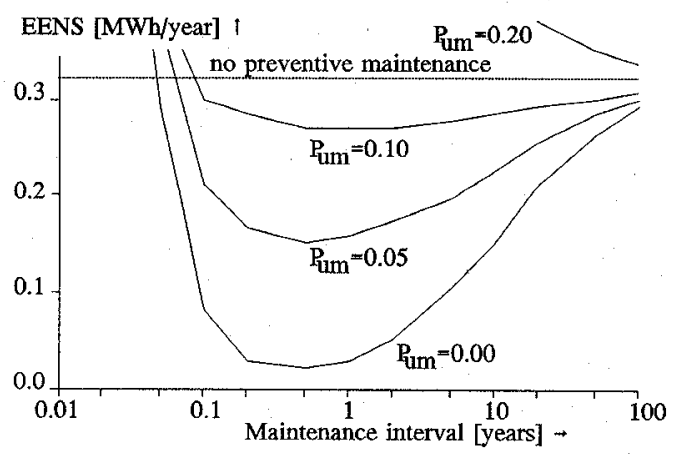

Figure 7. Expected energy not supplied per year (EENS) in the system for case study 3
Because the utilities pay more and more attention to cost reduction with at the same time providing the desired level of customer service, it is required that the expected energy not supplied is related to cost. When it is assumed that the interruption energy assessment rate (IEAR) [11] at each busbar is equal to $5 \$ / \mathrm{kWh}$ and the cost of one hour maintenance is $100 \$$, the results presented in figure 7 can be converted into the results presented in figure 8 . This figure gives the expected total cost per year (ETC) as a function of the maintenance interval (or maintenance frequency).

Figure 8 shows that an optimal maintenance interval can be determined for component protections, when preventive maintenance is carried out carefully. When preventive maintenance is not carefully carried out, it is meaningless. It should be noted that all lines in the graph converge to the line which corresponds with never carrying out preventive maintenance (dotted line). 


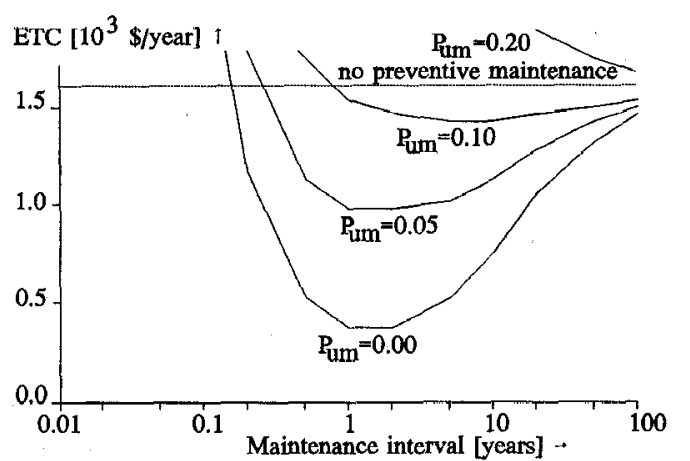

Figure 8. Expected total cost per year (ETC) in the system for case study 3

\section{Conclusions}

Protection system failures have a lot of impact on the reliability indices of load points in distribution systems. On the one hand, this is due to the fact that components are more frequently isolated due to false trips of the protection systems. On the other hand a lot of components can be isolated at the same time due to back-up clearing of the protection systems. In this paper, a comprehensive method for evaluating the effect of these failure modes has been developed.

The expected energy not supplied per year (EENS) can considerably be reduced by performing preventive maintenance on protection systems. However, it was seen that preventive maintenance must be performed carefully. Carelessly performed preventive maintenance on protection systems can even lead to an increase in the expected energy not supplied.

An optimal maintenance interval or frequency can bc detcrmined for component protections, when preventive maintenance is carried out carefully. From the viewpoint of reliability, this optimal maintenance frequency is about 2 inspections per year for the chosen system. From an economical point of view, this optimal maintenance frequency is about 1 inspection per 2 years for the chosen system. Studies for other system configurations have shown almost identical optimal maintenance frequencies.

\section{Acknowledgement}

The authors would like to thank the PNEM, a utility in the southern part of the Netherlands, for providing the financial support for this work.

\section{References}

[1] Dixon, G.F.L. and Hammersley, H., "Reliability and its Costs on Distribution Systems", IEE International Conference on Reliability of Power Supply Systems, Publication No. 148, 1977

[2] Anderson, P.M., "Reliability Modeling of Protective Systems", IEEE Transactions on Power Apparatus and Systems, Vol. PAS103, No. 8, pp. 2207-2214, August 1984

[3] APM Task Force Report on Protection Systems Reliability, "Effect of Protection Systems on Bulk Power Systems Reliability", IEEE Transactions on Power Systems, Vol. 9, No. 1, pp. 198-205, February 1994

[4] Anderson, P.M. and Agarwal, S.K., "An Improved Model for Protective-System Relibility", IEEE Transactions on Reliability, Vol. R-41, pp. 422-426, September 1992

[5] Allan, R.N., "Effect of protection systems operation and failures in composite system reliability evaluation", International Journal of Electrical Power \& Energy Systems, Vol. 10, No. 3, pp. $180-189$, July 1988

[6] Singh, C. and Patton, A.D., "Models and concepts for power system reliability evaluation including protection-system failures", International Journal of Electrical Power \& Energy Systems, Vol. 2, No. 4, pp. 161168, October 1980

[7] Billinton, R. and Tatla, J., "Composite Generation and Transmission System Adequacy Evaluation Including Protection System Failure Modes", IEEE Transactions on Power Apparatus and Systems, Vol. PAS-102, No. 6, pp. 1823-1830, June 1983

[8] Billinton, R. and Allan, R.N., "Reliability Evaluation of Engineering Systems: Concepts and Techniques", Longman, London, 1983

[9] Billinton, R. and Allan, R.N., "Reliability Evaluation of Power Systems", Pitman Books, Boston, 1984

[10] Endrenyi, J. "Reliability Modeling in Electric Power Systems", John Wiley \& Sons, Chichester, 1978

[11] Billinton, R., "Evalution of reliability worth in an electric power system", Reliability Engineering and System Safety 46, pp. 1523, Elsevier, 1994 


\section{Biographies}

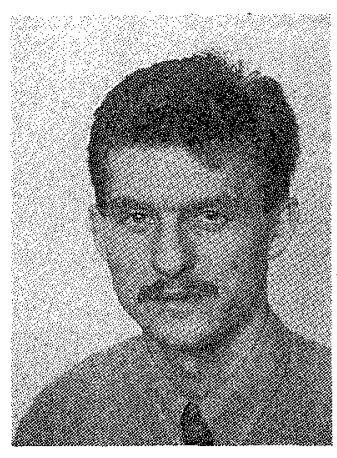

Jos Meeuwsen was born in

Goes, the Netherlands, on

December 29, 1971. He received his M.S.-degree in electrical engineering from the Delft University of Technology in 1994. Since then he has been with the Power System Laboratory of the same university. He is presently working on a

$\mathrm{Ph}$.D.-degree. His main research interest is the reliability assessment of electric power systems.

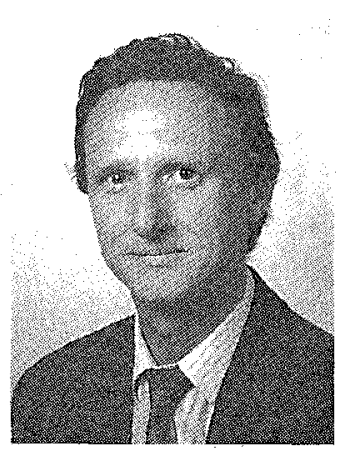

Wil Kling was born in Heesch, the Netherlands, on December 21, 1950. He received his M.S.-degree in electrical engineering from the Technical University of Eindhoven in 1978. For 5 years, he was at the KEMA as staff engineer in the technical and economic affairs department. Since
1983 he has been with Sep (Dutch Electricity Generating Board) in the planning and research department, where he is responsible for network studies and planning. Since 1993 he has been part-time professor at the Delft University of Technology. Mr. Kling is convener of the CIGRE/CIRED Working Group on the interaction between transmission and distribution planning.

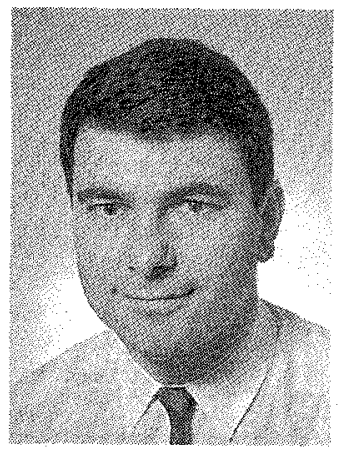

Wim Ploem was born in Schaerberg, the Netherlands, on May 18, 1960. $\mathrm{He}$ received his M.S.-degree in electrical engineering from the Technical University of Eindhoven in 1986. For 3 years, he was at DSM staff engineer in the electricity supply department. From 1989 to

1994 he was with an urban utility as manager of the planning department. He is currently an expert in distribution technology at PNEM. 


\section{Discussion}

John J. Kumm, Schweitzer Engineering Laboratories, Inc., Pullman WA: The authors have added an interesting new parameter to the discussion of selection of optimum protection maintenance interval: the probability of unsuccessful maintenance. Figure 7 clearly shows that frequently performed maintenance, if unsuccessful, is detrimental to power system reliability.

Relays equipped with self-testing capabilities have a lower periodic maintenance requirement [D1]. This reduced requirement is demonstrated by the longer optimum test interval and a higher system reliability when maintenance intervals increase toward infinity.

Utilities that experience high probability of unsuccessful preventive maintenance receive even larger dividends from application of self-testing relays. Maintenance that was previously detrimental is now no longer practiced or is only performed infrequently. Meanwhile, protection and power system reliability are increased through application of the more reliable relays. Resources formerly applied to dull maintenance tasks can now be applied to more interesting and meaningful tasks such as event analysis and protection scheme enhancement.
Because [D1] does not take into account the probability of unsuccessful maintenance, and the authors do not account for relay self-testing, we would suggest a consideration of the two effects together as an area for future study.

[D1] E.O. Schweitzer, III, J.J. Kumm, M.S. Weber, and D. Hou, "Predicting the Optimum Routine Test Interval For Protective Relays," IEEE Transactions on Power Delivery, v. 10, no. 2, 1 April 1995, pp. 659-664.

Manuscript received February 6, 1996.

J.J. Meeuwsen: The authors would like first to thank the discusser for his stimulating remarks and suggestion. The authors are still working on the subject of predicting optimal protection maintenance invervals. The authors agree with the discusser that a consideration of unsuccesful maintenance together with relay self-testing is an interesting area for future study.

Manuscript received April 15, 1996. 